\title{
The Proper Aim of Therapy: Subjective Well-Being, Objective Goodness, or a Meaningful Life?
}

\author{
Thaddeus Metz
}

\section{Therapy's Final End}

What should psychotherapists be aiming to achieve with their clients? In seeking to answer this question, this chapter enquires into whether there is good reason to believe in a certain final end that is appropriate for therapy.

In seeking out the final end of therapy, this chapter is not fundamentally interested in means that are particularly useful for attaining it. Making a client feel heard and interpreting a dream $\mathrm{s} /$ he has shared are often apt tools for obtaining a certain, ultimate goal, where this chapter is solely concerned to identify what that goal ought to be, not how to achieve it effectively.

Similarly, it is not concerned with moral constraints on the way that a therapist ought to pursue the proper aim of therapy. A therapist normally ought to keep facts about a client's past confidential and ought not to engage in a sexual relationship with him/her. These are plausible restrictions on the way a therapist should interact with clients, and clearly do not constitute what the point of the therapy is.

Some might suggest that there are myriad points of therapy, varying from client to client. That is of course true at one level, but is quite dubious at another. At a certain level of specificity, each client is of course different and calls for a particular aim on the part of the therapist. Some clients have an interest in overcoming a fear of intimacy, others an addiction, others a tendency to dominate, still others an inclination toward wishful thinking, and so on. However, stepping back, it is plausible to think that there are some commonalities among how clients are badly off and what a therapist ought to be striving to achieve with them. After all, dependence on alcohol is not qualitatively different from addiction to drugs; and then arguably those conditions are not all that distinct from being overly attention seeking or being

\footnotetext{
T. Metz, Ph.D. ( $\bowtie)$

Department of Philosophy, University of Johannesburg,

POB 524, Auckland Park 2006, South Africa

e-mail: tmetz@uj.ac.za
} 
submissive out of an unreasonable fear of abandonment. There are plausibly types of mental illness and hence some general final ends of therapy.

Even if the reader agrees with the point that there are, at a broad or theoretical level, not as many final ends as there are numbers of clients, s/he might still think that there are a plurality of general final ends, and not just one that captures the proper aim of therapy for every person who is a suitable client. It is true that there might not be just one. However, it would be intellectually fascinating if there turned out to be only one comprehensive final end of psychotherapy. And if there were just one, knowing what it is would naturally have some practical implications for the way therapy should be conducted.

This chapter therefore seeks to ascertain what the final end of therapy might be, on the supposition there may well be one. Specifically, it addresses three prima facie plausible theoretical candidates, and argues that one is preferable to the other two, which are currently more influential among therapists, psychologists, and related enquirers such as philosophers.

According to one of the two dominant approaches, the basic point of therapy should be, roughly, to help clients become clear about what they want deep down and to enable them to achieve it by overcoming mental blockages. The second section spells out this conception of therapy's final end in terms of subjective well-being, explains why it has been so influential, and then presents some counterexamples to it.

The third section takes up the other major theory of what a therapist ought to be aiming to achieve, namely, to psychologically enable clients to live an objectively good life, say, one that involves developing their inherent talents or exhibiting a true/ whole/strong self. After presenting counterexamples to this theory, it is noted that combining the two approaches would not avoid the objections, and hence that it would be worth considering a third approach that avoids, and indeed explains, them.

The fourth section advances the novel view that the proper aim of therapy is to mentally facilitate a meaningful life as it is broadly understood by contemporary philosophers. The suggestion is that fostering meaning in life, suitably construed in light of recent work in English-speaking philosophy, is not merely the appropriate final end of existential therapy (e.g., Yalom, 1980) and of logotherapy (Frankl, 1984), but of therapy as such.

The concluding section of the chapter provides an overview of its findings, indicates their limits, and makes some recommendations. It points out that what the two dominant views of therapy's final end have in common is a strict devotion to the client's welfare, construed either subjectively or objectively. It notes that seeking to enhance the meaningfulness of a client's life is not identical to-although does largely overlap with-promoting a client's good, and is what enables the favored theory to avoid the problems facing its rivals, while capturing their kernels of truth. However, it also concedes that this chapter has not provided enough evidence to convince a skeptic that there is only one final end of psychotherapy, let alone the one toward which this chapter is sympathetic. At best it shows that the category of meaning in life, as recently construed by philosophers, is under-explored as a ground of therapy's proper aim. Supposing, though, that this chapter has demonstrated that meaning is worth taking seriously as therapy's final end, it closes with some advice addressed to therapists. 


\section{Subjective Well-Being}

Subjectivism is broadly the view that the proper aim of a therapist depends on the subject, i.e., varies according to the particular client with whom s/he is working. After providing some examples of this approach, and indicating why it is prima facie plausible, this section makes some objections to it, ones that make an objective approach look more attractive by comparison (at least temporarily).

Subjective conceptions of therapy's point differ mainly according to which mental state is taken to ground it. For instance, in one text Sigmund Freud is naturally read as suggesting that the therapist's goal should be to relieve clients of suffering and to help them experience pleasant feelings without contortion, disturbance, or other symptoms (1930, pp. 32-33, 48; for similar recent views among contemporary analysts, see Bader, 1994 and Fink, 2010). Consider, too, the suggestion from D. W. Winnicott that one major aim of therapy should be to enable clients to feel alive or to experience vigor (Winnicott, 1955; see also Kohut \& Wolf, 1978). ${ }^{1}$ Finally, recall the hedonic conception of well-being held by many psychologists, perhaps most famously by Kahneman, Diener, and Schwarz (1999). In short, broadly speaking from all these perspectives, the therapist should be working with a client's mental life with the aim of producing pleasure and reducing pain, or at least alleviating suffering.

Carl Jung has also advanced what appears to be a subjective account of the therapist's proper aim, one focused not so much on the client's feelings or experiences, but rather his/her goals. Consider how Jung emphasizes the need for a client to prize his/her "inner voice" (1953, p. 156) or to place "his law above all conventions" (1953, p. 154). Jung also remarks, "The greatness and the liberating effect of all genuine personality consists in this, that it subjects itself of free choice to its vocation ...." (1953, p. 155), with the therapist's proper aim being to foster such a way of living. Also worth mentioning, here, are Rollo May's suggestions that it is "the function of the counselor to lead the counselee to an acceptance of responsibility for the conduct and outcome of his or her life" $(1989$, p. 21$)$ and that "the function of the counselor is to help the counselee be what destiny intended him or her to be" (1989, p. 22), where responsible choices and destinies will vary widely depending on the individuals involved.

For a third kind of subjectivism, consider an approach that focuses on a client's judgment. According to one influential version, the therapist's aim should be to enable the client to hold an appraisal of his/her life that is on balance positive. For many, such judgment centrally includes an emotional dimension, so that positive self-appraisal consists of the relative absence of negative emotions and the presence of satisfaction with one's life as a whole. Beyond many psychologists conceiving of happiness in this way (e.g., Diener, Suh, Lucas, \& Smith, 1999), those who have

\footnotetext{
${ }^{1}$ The suggestion is not that these perspectives exhaust either Freud's or Winnicott's views (indeed, section three addresses the latter's more objective view that the point of therapy is to live according to a true self); it is rather that their texts occasion awareness of subjective approaches, ones that have been extremely influential. More generally, this chapter is not out to capture the intricacies of any particular theorist, but rather to draw on remarks and views so as to illustrate theories.
} 
addressed therapy directly have sometimes suggested that its proper aim is to make it psychologically possible for the client to deem his/her life to be at least less bad, and ideally good on the whole. "The job is to make some sense out of the often vague feeling that one's life is not being lived as well as it could be. To what extent can we say that this is the result of an emotional disturbance that can be approached therapeutically?" (Kovel, 1976, p. 34).

For a related view, consider the one that the philosopher Jürgen Habermas seems to propose when he says, "Analytic insights possess validity for the analyst only after they have been accepted as knowledge by the analysand himself" (1971, p. 261). If an interpretation is valid "only to the degree that those who are made the object of individual interpretations know and recognize themselves in these interpretations" (Habermas, 1971, pp. 261-262, see also pages 267 and 269), and if an interpretation also includes a view of how a client ought to move forward, then it follows that the proper aim of therapy for a given client is essentially one that $\mathrm{s} / \mathrm{he}$ has judged to be correct.

This adumbration of types of subjectivism should be enough to illustrate the ways that this general approach has been influential among psychotherapists, psychologists, and philosophers, too. It should also be sufficient to reveal why it has been worth taking seriously as a theory of what therapists ought to be striving for with their clients. First off, a typical client enters therapy because s/he is miserable, cannot achieve what s/he most wants, or is dissatisfied with his/her life, and therapists naturally tend to view themselves as allies in the struggle against conditions experienced as negative by the client.

Second, subjectivism makes good sense of "one of counselling's most sacred rules, which is that the counsellor should respect the client's values" (LeBon, 2001, p. 38; see also p. 107). Instead of imposing his/her own values, the therapist is normally expected to work within the client's set of desires and ideals, the appropriateness of which subjectivism easily explains.

For a third consideration in favor of subjectivism, note that a plausible explanation of what makes something a mental illness or otherwise worth treating is that it interferes with a particular client's subjective orientation in some way. It is plausible to think that: a fear of intimacy is something to overcome because it inhibits a client's ability to feel as much pleasure as s/he could; an addiction is something to beat because it is incompatible with a client's more basic goal in life; an inclination to dominate others is something to rebut because a client is dissatisfied with him/herself for exhibiting it; a fear of being in public is something to deal with because it prevents a client from enjoying what the world has to offer; and a tendency for a client to harm him/herself consequent to feeling abandoned is something to treat because of the suffering involved.

Fourth, and finally, subjective well-being has been, and still remains, the dominant understanding of the nature of happiness by psychologists (so report Adler et al., 2013). Supposing, as is reasonable on the face of it, that the job of a therapist should be to enable his/her client to be happy or to fare well, or at least not to be all that unhappy, a subjective approach is what contemporary psychology on the whole recommends. 
However, there are serious objections to any subjective theory, construed as a comprehensive and fundamental account of the final end of psychotherapy. Philosophers and even psychologists sometimes postulate "fantastic" hypothetical counterexamples to it. For instance, if subjective states were all that mattered, then feeding people soma in a Brave New World would be appropriate (Adler et al., 2013), as would putting them into an "experience machine," viz., a virtual reality device that would impart only positive feelings and emotions during the course of their lives (Nozick, 1974, pp. 42-45; see also LeBon, 2001, pp. 29-30; cf. Metz, 2013a, pp. 163-179).

Although such thought experiments have their proper place in theoretical reflection, one need not seek out such unrealistic counterexamples in order to question subjectivism. Here are more likely examples, even if they would still be somewhat rare to encounter in an actual therapeutic context.

Consider someone who regularly undergoes manic states, which s/he experiences as pleasant, and who does not "crash hard" after them. Suppose there were a person addicted to heroin who had an unending and regular supply of the drug available. Think about those who exhibit schizoid tendencies, say, who proclaim to "love" a lifelike doll that is ever present and who forgo relationships with "unreliable" persons in favor of it. Reflect for a moment on a psychopath who judges his/ her inclination to manipulate others to be just fine. Imagine a narcissist who succeeds in substantially achieving his/her aim of doing whatever it takes to enhance his/her sense of self-worth, including by treating others merely as a means to it. Imagine someone who is histrionic but lucks out in finding someone able and willing to give him/her the attention s/he so desperately craves.

When focusing on subjective factors, the key issue becomes one of stability, of encountering a world reliably instrumental for producing pleasure in oneself, achieving one's ends, or fostering satisfaction with one's life. Where the world does not cooperate, as it were, e.g., when an addict cannot obtain the drug or when a narcissist is rejected, then the subject undergoes a negative state. What the cases above show, however, is that mental illness can obtain even when the world does cooperate, viz., when the addict has plenty of the drug and the narcissist or psychopath becomes a "successful" CEO. A person can be apt for psychotherapy, e.g., can intuitively be "sick," even in situations where his/her pleasure, goals, or satisfaction are not threatened. If so, then subjectivism cannot be an adequate account of therapy's point.

One might reply on behalf of the subjectivist that it would be wrong for someone to interfere with these individuals. If someone were content being in a "relationship" with a doll, who may rightfully stop him/her?

However, this reply conflates two distinct issues. One issue is whether a person should be forced into therapy or otherwise coerced into changing. The other is whether a person would be a good candidate for therapy in light of a certain conception of therapy's point. Just because someone has strong reason to undergo therapy does not mean that others may legitimately force him/her to do so.

Another reply on behalf of the subjectivist might be to suggest that the above kinds of persons would not be in therapy if they were not undergoing some kind of negative condition such as experiencing pain, or failing to get what they ultimately want, or 
sensing that their lives are not going well. If someone is seeking out therapy, then deep down s/he is undergoing pain, frustration, despair, so the argument goes.

There are two responses to make to this tempting reply. One is that not everyone who is in therapy is there because of "instability," i.e., because his/her positive subjective conditions are being thwarted. A person might seek out a therapist not because $\mathrm{s} / \mathrm{he}$ finds him/herself disturbed, but rather because others have suggested that $\mathrm{s} /$ he see one. That is, $\mathrm{s} / \mathrm{he}$ might have taken some third-personal advice about $\mathrm{him} /$ herself (say, given by the author of this chapter). Or a court might have ordered $\mathrm{him} / \mathrm{her}$ to undergo some kind of rehabilitation that includes therapy. Or a person might be temporarily confused about what s/he ultimately values, and then finds, upon reflection with a therapist, that s/he really does hate women more than love them and so will continue to act on the former orientation.

Subjectivists might be tending to assume that human nature is essentially good, that what all people ultimately prefer is intuitively desirable. But one need not believe in the Freudian id in order to deem that to be a form of wishful thinking. That is true even when focusing on the "preferences which we would keep if we were reflecting under idealized conditions of being well informed, cool, calm, and collected" where "the counselling room provides the perfect arena for such reflection" (LeBon, 2001, pp. 35, 39). Some people are so damaged that their deepest subjective dispositions are fundamentally unhealthy or otherwise merit treatment. ${ }^{2}$

The second response is that the present reply, upon reflection, is not really relevant. The question is not, "Given that people are in therapy, why are they there?"; it is rather, "Given a certain conception of the point of therapy, who should be in it (even if they are not yet)?". The claim in this section is that a subjective conception of therapy's point cannot easily make sense of the intuition that a person could be a good candidate for therapy even if $s /$ he were not disposed toward subjective upset. The lucky addict and narcissist are just two illustrations of individuals who are subjectively well off but who are nonetheless mentally ill or otherwise have reason to seek out therapeutic intervention.

In light of the above counterexamples, there appear to be some conditions in which one ought not take pleasure, some goals that one should give up, and some states with which one has reason to be dissatisfied. Recurrent mania could be pleasant, but it would come at the cost of a loss of groundedness (setting aside the chances of consequent depression). One might be able to achieve consistently the goal of enhancing one's self-interest by means of manipulating others, and feel a great sense of self-satisfaction thereby, but one should not have such a higher-order goal and such a strong emotion. And one might not feel any shame at being subject to a compulsion to receive constant attention from others that one ends up receiving, but it would be reasonable to become the sort of person who does.

\footnotetext{
${ }^{2}$ Note that merely because an attitude is deep does not necessarily mean that it is fixed. Even if one strongly likes something or takes an interest in it for its own sake, it might still be possible to change one's likes and interests.
} 
These are the kinds of judgments that an adherent to a more objective conception of the point of therapy would make. In particular, they suggest the theory that the point of therapy is to foster a client's welfare, construed in terms that are in an important respect independent of his/her particular feelings, goals, and judgments.

\section{Objective Goodness}

The other influential conception of the final end of psychotherapy has been one focused on what would be objectively good for the client. "Objective" here indicates that there are certain ways of being and living that would be desirable for a person, and not merely because s/he would feel pleasure upon exhibiting them, want to do so, or approve of them. Instead, the idea is that there are ways of functioning well that are appropriate "in themselves" and that one perhaps has reason to be pleased by, to want to do, or to approve of, if one does not already.

Such a theoretical approach emerged most clearly in the 1950s, and from those from a variety of clinical and academic backgrounds. On the one hand, there were neo-Freudian analysts, such as Karen Horney, who conceived of the proper aims of therapy as enabling a client to work, to relate to others, and to be responsible (1950), and Erich Fromm, who in one text maintained that the ultimate aim should be to enable clients to love (1956). On the other hand, there were humanist psychologists who advanced objective conceptions of mental health and (at least by implication) of therapy's point. Consider, here, Abraham Maslow having proposed 14 properties of psychological health, such as creativity and moral concern, as elements of selfactualization (1950) and Carl Rogers having advocated a focus on the abilities to cope with stressors and to rely on oneself (1957).

Then there were also the various forms of self-psychology that therapists and psychologists developed in the post-war era. W. R. D. Fairbairn (1958, p. 380) and Anthony Storr (1960, pp. 156-160), for just two examples, focused on the idea that psychopathology consists of a fragmented or conflicted self, with the aim of therapy being to develop synthesis or wholeness in the client's self. D. W. Winnicott distinguished between the true self and the false self, where the therapist should strive to bring out the former (1960; for more recent proponents, see Masterson, 1990; Miller, 1979). And still others emphasized mental health as a strong or firm self as opposed to a weak or feeble one, with Heinz Kohut being one clear example (1977; see also Kohut \& Wolf, 1978, pp. 361-363). ${ }^{3}$

Finally, as a contrast to hedonic and more generally subjective approaches to well-being in psychology, eudaimonism has become influential of late, particularly among positive psychologists. According to this broad perspective, mental health is a matter of being psychologically able to realize oneself through activities of various

\footnotetext{
${ }^{3}$ Sometimes these thinkers appeal to more than one characterization of a healthy self, the thought being that, say, a disintegrative self is a (kind of a) weak one. It would be interesting to consider elsewhere whether one construal is more apt than the others or is most fundamental.
} 
kinds. For instance, living well might be a matter of exercizing virtue, actualizing one's inherent talents, or living autonomously (e.g., Boniwell \& Henry, 2007; Delle Fave, Massimini, \& Bassi, 2011; Ryan \& Deci, 2001; Ryff, 1989, 2014). Instead of a focus on states of feeling pleasure or being satisfied, eudiamonism concentrates on processes such as certain ways of functioning or interacting that are intrinsically good for a person (Delle Fave et al., 2011).

Another way to understand eudaimonism is in terms of higher and lower natures. On the one hand, a person has a lower nature that is either shared with animals or is deemed to be undesirable for being metaphorically animalistic or inhuman. On the other hand, a person also has the capacity to exhibit valuable traits, features that are genuinely human. According to eudaimonism, one is living well when one is flourishing as a human in a way that no animal can, say, for playing the piano, exhibiting integrity, or being part of a loving relationship.

Conceiving of the ultimate point of therapy in terms of objective goodness grounds explanations of mental illness that powerfully rival the subjective ones canvassed in the previous section. A fear of intimacy is undesirable not so much because it inhibits a client's pleasure, but rather because it prevents him/her from realizing him/herself as a loving person. An addiction is something to overcome not merely because it conflicts with a deeper goal that a client happens to have, but mainly because it is incompatible with his/her higher (rational) nature. An inclination to dominate others is something to rebut not because a client is dissatisfied with him/ herself for exhibiting it, but rather because s/he ought to be dissatisfied with him/ herself for being unable to relate to others on egalitarian terms. A fear of being in public is something to deal with not so much because it prevents a client from enjoying what the world has to offer, but rather because it prevents him/her from actualizing him/herself through a variety of potential activities. Finally, a tendency for a client to harm him/herself consequent to feeling abandoned is something to treat not just because of the suffering involved, but because of the weak self or neediness determining his/her interaction with others.

In addition to grounding compelling accounts of conditions that merit psychological intervention, taking an objective approach to therapy's point enables a theorist to avoid the objections facing a focus on subjective well-being. For example, someone addicted to a never-ending supply of heroin might feel pleasure, but would not be doing much with his/her life. A narcissist whose desire for self-aggrandizement were routinely satisfied would still be acting consequent to a weak self at the core of his/her character. A person who elects to "love" a doll rather than a person would not be engaging in a relationship, or at least not a genuinely important one.

Despite these substantial advantages accruing to objectivism, it is also vulnerable to counterexamples, if construed as an exhaustive account of what therapists ought ultimately to be striving to achieve with their clients. There are intuitively occasions when it would be right for a therapist to aim to help clients knowingly do what would fail to help them live a life that would be objectively good for them.

What these cases have in common is the idea that sometimes it can be reasonable for clients to want to sacrifice their own objective good. More specifically, there are times when people are sensible to forsake the prospect of an objectively good life 
for themselves so as to help others. ${ }^{4}$ And therapists would not be inappropriate to assist them in doing so.

For a first, "hypothetical" case to make the point clear, consider someone, A, who needs therapy in light of objective considerations, but who knows someone, B, who also needs such therapy. Suppose B cannot afford or otherwise access therapy without A's help, but that for A to help would mean being unable to afford or otherwise access therapy him/herself. And now suppose A is in therapy discussing precisely this situation with his/her therapist, viz., whether A should discontinue therapy so as to enable B to undergo it.

Supposing that A does not need therapy desperately more than B, it would be reasonable for a therapist not to discourage A from discontinuing therapy and perhaps for him/her even to help A find ways to make it most efficient for B to obtain it. To do so would appear to be an instance in which the therapist is not acting for the sake of an objectively good life for A.

In reply, the objectivist would surely suggest that in making such a sacrifice for another, A would be thereby living objectively well. A would be trading off one sort of objective goodness, which would obtain via therapy, for another, which would obtain by forgoing it.

This is a prima facie compelling reply, but it is not clearly successful. First off, one might question whether making such a sacrifice would really be an instance of objective goodness; if one thinks of the latter in terms of a certain kind of self or character that is extremely hard to develop over time, as in the psychodynamic tradition, then one might well not.

However, let us grant, for the sake of argument, that making such a sacrifice would be to exemplify some objective goodness. The second response, then, is that it would be reasonable for a therapist to help A make such a sacrifice even if A would thereby obtain less objective goodness than s/he would if s/he stayed in therapy. Again, granting that making the sacrifice would be good for A, it could well be better for $A$ were $\mathrm{s} /$ he not to make the sacrifice. In such a situation, however, a therapist would not be unreasonable to help A make the sacrifice, or at least not steer him/her away from doing so.

Here is a second counterexample. Imagine a soldier who will soon be going off to war in order to fight for a just cause. S/he is wondering precisely how much sacrifice to make for this cause and for his/her fellow soldiers. In particular, s/he is considering whether to be willing to jump on a grenade, if doing so would save his/her comrades and best enable his/her side to push forward. In this situation, it would be reasonable for a therapist not to try to persuade the client to stay alive. But staying alive would of course be necessary for living objectively well; after all, one cannot play the piano, develop an authentic or integrated self, or be part of a loving relationship if one is dead.

\footnotetext{
${ }^{4}$ Another sort of case, which I lack the space to address in depth here, is one in which a client is inclined to give up objective goodness in favor of a religious, cultural, or other value with which $\mathrm{s}$ /he identifies. A medical doctor intuitively can have reason to treat patients in light of their meaningful self-conceptions, and so not to promote their physical health as much as s/he would have otherwise (on which see Orr \& Genesen, 1997); similar remarks arguably apply to a therapist.
} 
Again, it is tempting for the objectivist to reply that committing suicide would be an instance of objective goodness. Here, however, it is even less plausible than in the previous case to think that it would be good for him/her at all. It is natural to think of eudaimonia, self-realization through certain kinds of activities, as something that makes a life worth continuing, but such cannot be something that makes life worth ending (cf. Metz, 2012). And then one is hardly developing a strong self as prescribed by self-psychology if one kills oneself.

These far-fetched cases have been constructed in order to motivate clearly the point that it can sometimes be reasonable for a therapist not to aim for what would be most likely to make a client objectively best off in the long run. More everyday and familiar illustrative cases abound, upon reflection. Consider, for instance, someone trying to make the decision of whether to become chair of an academic department, having to take on administrative burdens and attend dull meetings so that his/ her colleagues can avoid doing so. Even if this person would exhibit some moral concern and hence objective goodness by becoming the chair, s/he might be giving up more objective goodness on the whole, as s/he would have made substantial scholarly or creative contributions, or been able to deal with his/her moderate depression, if s/he had had the time and mental freedom.

Less glibly, think about those in the caring professions, such as nurses who elect to face stench, filth, distress, misery, and the like so that such conditions are lessened for others. There can, of course, be some self-realization that comes in the form of emptying bedpans and otherwise caring for others in desperate need. The point is that it could be reasonable for one to empty bedpans even if one would obtain even more self-realization if one did not, and furthermore reasonable for a therapist not to counsel a person otherwise and instead to enable him/her to confront the challenges $\mathrm{s} /$ he has elected to confront. Similar remarks apply to those who have firmly decided to stay in a marriage that is unfulfilling and even threatens self-esteem a few more years for the sake of their children, and who are seeking help from a therapist in making the best of a situation they have chosen that is, let us suppose, good for the kids but not good for them.

An interesting reply for the objectivist to make at this point would be to contend even if the therapist as a person should sometimes help clients forsake their own objective good, s/he ought not do so as a therapist. Qua therapist, one ought to focus strictly on a client's self-realization or self-development, but sometimes one can have good reason to let go of the role of therapist, so the reply goes. ${ }^{5}$

But is it intuitively the case that one would not be engaging in therapy any longer if one accepted a soldier's firm inclination to commit suicide for a just cause or a parent's unwavering commitment to stay in a crummy relationship? Should one not charge clients for the time spent during which one was enabling them to sacrifice their objective good for the sake of others? Should one be reported to the profession for having engaged in misconduct?

Subjectivists will naturally point out, here, that salient versions of their view can readily accommodate these counterexamples. They appear to be cases in which a

${ }^{5}$ I must credit Michael Lacewing for this fascinating suggestion. 
therapist should support clients' deepest desires and firmest judgments about their lives, even though their choices might not be objectively good for themselves.

However, despite this advantage, the objections to subjectivism from the previous section remain; it is not just any subjective orientation on the part of a client that plausibly orients his/her therapy. That means it would be ideal to develop a theory of therapy's final end that avoids the objections facing both subjectivism and objectivism, while capturing their advantages, something sketched in the following section.

\section{Meaning in Life}

The deep lesson to be learned from the previous two sections is that it is implausible to think that the proper aim of a therapist should be reduced to doing whatever would be good for a client. Of course, much of what a therapist should be doing is equivalent to making a client well off in some sense. However, the objections to subjectivism and objectivism suggest that at least sometimes the point of therapy should not be to maximize a client's happiness, interests, welfare, excellence, or the like, whether subjectively or objectively construed. Against subjectivism, sometimes a client's attitudes are not ones to be promoted, and against objectivism, sometimes a client is sensible to want to sacrifice his/her own self-realization or self-development for the sake of others.

The rest of this chapter articulates a different approach to therapy's final end that promises to capture the kernels of truth in both subjectivism and objectivism while avoiding the counterexamples to them. Whereas subjectivism and objectivism are plausibly understood as theories of well-being, or of what makes a life worth living, the focus here is instead on the category of meaningfulness, as conceived by contemporary Anglo-American philosophers. ${ }^{6}$ Often what makes a life meaningful will make it good for the individual whose life it is, but not always.

For many in the field of philosophy these days, talk of "meaning in life" largely connotes ideas about what it would be reasonable for a person to take great pride in, what it would be sensible to admire in others, or what merits reverence, awe, and similar kinds of emotions (Kauppinen, 2012, pp. 353-358; Metz, 2001, 2013a, pp. 24-35; Taylor, 1989). Note how these kinds of ideas differ from what it means to speak of "happiness" or "well-being"; the bare fact of living well does not intuitively merit reactions of esteem, admiration, or respect.

By speaking of a "meaningful life" philosophers do not essentially mean one that is merely perceived as meaningful. Some psychologists, for instance, think of a good life as one in which the person judges him/herself to be engaging in meaningful activities (e.g., Baumeister \& Vohs, 2002; Delle Fave et al., 2011, p. 8). However, instead of focusing on finding aspects of a life to be meaningful, consider meaning in a life period, a matter of living in a way that merits a certain emotional response

\footnotetext{
${ }^{6}$ And hence not by, say, Viktor Frankl (1984).
} 
such as pride, admiration, or awe. Philosophers tend to find it plausible to suppose that a life could be meaningful but not judged to be by the person living it, with Vincent Van Gogh being a reasonable example, and, conversely, that a life could be found meaningful that was not in fact so, probably Adolf Hitler.

In presenting a substantive conception of what makes an individual's life meaningful, the following draws mainly on work by contemporary English-speaking philosophers. More specifically, it focuses on common ground among many of the most prominent and influential ones to address the topic of meaning in life over the past 25 years or so. ${ }^{7}$

For many philosophers now writing on what constitutes meaning in a person's life, it is thought to largely involve the rigorous exercise of one's intelligence, ideally directed toward the classic triad of "the good, the true, and the beautiful" and in a way that makes for a compelling life story. The following spells out each of the key elements of this terse statement.

Intelligence, or rationality, includes reflecting on one's aims, planning so that many aims are realized in the long run, acting in light of one's deliberation, and exhibiting strength of will. It also includes certain capacities, beyond deliberation and volition, that some readers might suspect are being excluded, such as emotions. Love and artistic expression are sometimes called "irrational" or "nonrational," but these are sensibly deemed to be parts of our rational nature, insofar as they include an element of judgment (e.g., that a beloved is good, that a brushstroke is apt) and can be modified by cognitive reflection (at least indirectly, over time). Many human emotions are, in these ways, forms of rationality that differ substantially from autonomic functions, reflexes, and moods. In short, talk of "emotional intelligence" and "social intelligence" is to be taken literally.

The mere process of rigorously using one's intelligence can probably confer some meaning on one's life; excelling at sports and games can intuitively make one's life meaningful, viz., be something in which to take substantial pride. However, for many in the field, notable meaning normally comes when one's rational nature is positively oriented toward certain ends (other than placing a ball into a small space in the face of obstacles), most saliently the following: "goodness," viz., helping others in the form of, say, loving a family, working for a charity, or being employed in a caring profession; "truth," which means informedly reflecting about oneself, society, or nature, perhaps by obtaining a formal education, making a scholarly discovery, or becoming more wise; and "beauty," shorthand for being creative by, for instance, making art objects, decorating a room, or expressing humor.

Finally, another key idea in contemporary philosophical reflection on meaningfulness is that it can inhere in the pattern of one's life or the narrative one's life makes up. For example, there is plausibly meaning in the fact of one's life having progressed over time, from having started out bad in one's adolescence and having ended on a high note in one's old age. For another example, there is intuitively meaning in having redeemed bad parts of a life by making good come of them in later parts. For yet another example, there seems to be meaning in standing up for

${ }^{7}$ Which was first spelled out in Metz (2013b), from which the next few paragraphs borrow. 
what one believes to be right throughout the course of one's life despite recurrent temptations to do otherwise. These are just three examples of "life stories" that appear meaningful, or at least to merit much greater esteem or admiration than the converse patterns (viz., of starting off well and ending on a low note, seeing good in one's life produce lots of bad, or flip-flopping in an opportunistic way).

Although many professional philosophers currently writing on meaning in life would accept the above ideas, there of course remain substantial differences beyond them. There is disagreement about what, if anything, all three elements of the good, the true, and the beautiful have in common at bottom. There is debate about whether there could be any of these values without God, or whether they can be adequately realized in a physical world, absent a heaven. Some emphasize certain elements of the triad more than others. And theorists naturally tend to conceive of elements of the triad in detailed ways that compete. ${ }^{8}$

Before applying this broad conception of meaning in life to issues of psychotherapy, note some salient ways that it differs from objectivism, its theoretical cousin. The view that one's life is more meaningful, the more one exercises rationality in beneficent, reflective, and creative ways that, as a pattern, make for an interesting life story is not identical to the view that one is mentally healthy or well off insofar as one develops an authentic/integrated/resilient self or realizes oneself through certain activities. To be sure, the latter could instantiate elements of the former. The point is that the latter, at least as characteristically conceived, do not exhaust the former.

For one, a focus on developing a certain kind of self is often considered intrinsic to the client, as a state internal to his/her mind, which is particularly the case for psychodynamic theory and self-psychology. In contrast, much of meaning in a person's life is extrinsic, a matter of a client relating to something beyond, perhaps greater than, him/herself, such as the good, the true, or the beautiful.

For another, neither self-development nor self-realization is usually cashed out in terms of displaying narrative value in one's life. Invariably, a self-focused approach to mental health or well-being concentrates on certain states of mind or activities considered in themselves, and not as a pattern they compose over time. Of course, attention often must be paid to a client's history in order for him/her to develop a particular sort of self; the point is that such attention to a "life story" is merely a means to an end for developmental- or self-psychology, whereas for most theorists of meaning it can be something worth developing for its own sake, with redemption being a key theme.

For a third, meaningfully contributing to the realization of certain ends by the substantial use of one's intelligence need not, and indeed sometimes cannot, be conceived in terms of self-development or self-realization. Returning to the case of Van Gogh, his life was plausibly meaningful (admirable) not merely in virtue of the great paintings he produced during his lifetime, but also the unforeseeable posthumous influence they had on the art world and the more general public. It is quite implausible to think that this influence - after Van Gogh's death-was constituted

\footnotetext{
${ }^{8}$ These matters are critically explored in Metz (2013a).
} 
by a true/whole/strong self or self-actualization on his part (even if it was caused by such a condition).

Consider, now, how the present conception of meaning in life grounds explanations of why certain people intuitively are good candidates for therapy, explanations that contrast with those appealing to what is objectively good for a person. A fear of intimacy is undesirable not merely because it prevents one from realizing oneself as a loving person, but also because it prevents one from participating in a meaningful relationship. An addiction is something to overcome not ultimately because it is incompatible with a person's higher nature, but mainly because it would undermine his/her rationality and particularly his/her ability to exercise it in substantial ways toward the good, the true, or the beautiful. An inclination to dominate others is something to rebut not because one ought to be dissatisfied with oneself for being unable to relate to others on egalitarian terms, but because it is something in which one cannot reasonably take pride and should probably instead feel shame. A fear of being in public is something to deal with not fundamentally because it prevents one from actualizing oneself through a variety of potential activities, but because meaning is largely a matter of relating to something beyond oneself, with isolation (e.g., prison) being a source of meaninglessness. Finally, a tendency for a client to harm him/herself consequent to feeling abandoned is something to treat not just because of the weak self or neediness determining his/her interaction with others, but because these conditions threaten his/her ability to live a life that one could sensibly admire for having made accomplishments.

Supposing these explanations are plausible, the category of meaning cannot, at least as yet, be criticized for failing to capture the major advantages that subjectivism and objectivism claim. It appears at least on a par with them so far. In addition, though, it can easily avoid the counterexamples facing the latter theories.

Recall that subjectivism faces the objection of lucky addicts, narcissists, and the like, those whose attitudes intuitively merit therapy despite not being frustrated by an uncooperative world. The advocate of meaning in life can say that such individuals, even if happy or well off in subjective terms, are not living nearly as meaningfully as they could. The addict with a never-ending supply of heroin would fail to exercise his/her intelligence substantively for, say, creative ends, while the narcissist with a never-ending supply of adoration would fail to do so in positive ways toward others' good.

And then recall that objectivism faces the problem that sometimes it can be apt for a therapist to help clients sacrifice their objective interests for the sake of others, which means that something other than objective goodness can be the point of therapy. The present suggestion is that meaning is a promising category. Why should a therapist enable a client to give up his/her own self-development or self-realization so as to help others? A plausible explanation is that the proper aim of therapy is to foster meaning in life, where such sacrifice can confer substantial meaning. ${ }^{9}$ Although it is often said of meaningfulness that it is something worth living for, it can also be something worth dying for (as Joseph Heller has famously suggested in Catch-22).

${ }^{9}$ The next two sentences are cribbed from Metz (2012, p. 445). 
Some meaningful conditions are naturally understood to be able to provide reasons to commit suicide, to let oneself die, or to otherwise make a large sacrifice of one's objective interests, since doing so might impart certain narrative qualities to one's life or produce good consequences for others' lives.

Before concluding, consider a few important objections to this section's hypothesis and replies to them. First off, it appears that a defender of this section's claim is committed to the view that a therapist ought not act for the sake of a client's mental health or psychological well-being, which is of course grossly counterintuitive.

However, the friend of the meaning view is not committed to that way of putting things. Instead, s/he can sensibly maintain that a therapist ought to act for the sake of a client's health or well-being insofar as it would be expected to contribute to meaning in his/her life, as it indeed often (but not always) would.

A second concern is whether the present view can make adequate sense of the "sacred rule" mentioned above, viz., that a therapist ought not to impose his/her own values on a client and should instead respect the client's. It might seem that only subjectivism can accommodate that intuition; considerations of meaning in life (as well as objective goodness) instead appear to entail that the therapist is, or should be, an expert on how to live, with few therapists thinking of themselves that way.

In reply, the view that the point of therapy is to foster meaning in a client's life does not require one to hold the view that a therapist invariably knows best. It could be, and probably often is the case, that what would make a particular client's life meaningful is something that can be discovered only in the course of dialogue between the two in a holding environment. Even if a therapist adheres to an abstract view of meaning, what it means for a given individual cannot be known by a therapist independent of drawing a client out, listening carefully to him/her, and considering his/her point of view.

As for the maxim of respecting a client's values, the category of meaning can plausibly account for it. A meaningful relationship between two adults is not one in which one person foists his/her views onto the other or treats the other as incapable. Instead, using one's intelligence in the realm of "the good" normally means doing what is expected to genuinely help another and in ways that the other recognizes and wants.

In addition, it is worth noting that respect for a client's values need not mean unconditional acceptance of them. If a client is keen on cheating on his/her spouse, torturing small animals for fun, acting out of racial hatred, or watching as much TV as s/he can while drinking beer, it would not be unreasonable for a therapist to press him/her on the issue. Inviting a client to consider whether a course of action would be meaningful or merit pursuit can be respectful; a therapist need not, and probably should not, automatically accept whatever his/her client wants deep down (in light of either defenses, on the one hand, or simply a lack of reflectiveness, on the other). Even trying to persuade a client that a certain course of action would be better than another could be respectful of his/her ability to make choices for him/herself, or could otherwise treat him/her as an equal rather than as an inferior. 
For a third worry about the category of meaning as a plausible conception of therapy's final end, return to the point that most clients enter therapy because of subjective considerations; they are miserable, cannot obtain what they most want, or are dissatisfied. Sometimes clients do begin therapy because they detect a lack of meaning in their lives, but that appears to be less often the case. Is not the point, or one major point, of therapy simply to relieve suffering?

It would not be unreasonable to posit more than one final end of therapy, as the conclusion notes. However, what those sympathetic to the meaning view can say is that suffering is something to overcome insofar as it is meaningless, reduces meaning, or is an obstacle to meaning. Pointless suffering is what should be combated, not suffering as such, or so the reader should consider.

\section{Conclusion}

This chapter has supposed that it is reasonable to suspect that there is a single comprehensive final end that is appropriate for psychotherapy, and has considered three accounts of what it might be. It has spelled out and motivated the two dominant theories, namely, of subjective well-being and objective goodness, but then presented counterexamples to them. The counterexamples suggest that a therapist ought not be aiming merely to do what is good for a client, either subjectively or objectively construed. Instead, this chapter has argued that a therapist ought at bottom to be doing what is likely to enhance the meaning in a client's life, understood in light of recent philosophical analysis, where that often, but not always, means doing what would be good for a client in some way.

The reflections in this chapter are probably not sufficient on their own to convince a skeptic that there is a single proper aim of therapy, let alone that the category of meaning in life, as spelled out here, captures it. In particular, one might still be tempted to hold the pluralist view that a therapist ought to promote a balance of subjective well-being, objective goodness, and meaningfulness in a client's life. More work would need to be done in order to see whether meaning can indeed supplant, and not merely supplement, the two dominant theoretical approaches to the proper aim of therapy. The hope is that the reader accepts that such work merits being undertaken.

At the very least, supposing meaning is a plausible contender for a, if not the, final end of therapy, there are certain strategies that therapists might usefully keep in mind. For one, they might invoke the terminology developed here in order to help clarify dilemmas for clients. That is, there can be situations in which clients cannot avoid trade-offs between subjective well-being, objective goodness, and meaning in life, and simply being able to name these different, competing values can be a way of obtaining understanding and moving forward.

For another, therapists could invoke "deathbed reflection" on the part of a client, asking him/her to consider what about his/her life s/he would like to be able to take pride in before dying, or what about it s/he would like others to be able to admire 
in a eulogy. Not only does such a perspective encourage attention to what is intuitively important, but it also fosters reflection on narrative values, including posthumous ones.

For a third, therapists may remember the remark often ascribed to Friedrich Nietzsche, "He who has a why to live can bear almost any how." There will be occasions when clients continue to suffer or do not develop stronger selves, despite substantial therapeutic intervention. Nonetheless, they might still be capable of engaging in meaningful activities, achieving purposes that help others, disclosing truth, or creating beauty, at least from time to time. That would be something for clients, and therapists, to grab on to when times are hard. ${ }^{10}$

\section{Key Takeaways}

- There are three theoretical interpretations of the ultimate aim of psychotherapy that are usefully distinguished, which focus on subjective well-being, objective goodness, and a meaningful life, respectively.

- The idea that psychotherapy as such, and not merely a particular instance of it, properly aims to impart meaning to clients' lives is not as popular as the other two approaches and is underdeveloped.

- Meaning in life here is understood in terms of contemporary English-speaking philosophy, where many hold the broad view that one's life is more meaningful, the more one exercises one's rational nature (which includes one's emotional life) in beneficent, reflective, and creative ways that, as a pattern, make for an interesting narrative or "life story."

- The more familiar and influential two theories of therapy's point both focus on what is conceived as good for the client, and it is this welfarist orientation that makes them vulnerable to objection. Sometimes what clients want deep down is not something that a therapist should help them fulfill, and it can also be reasonable for clients to want to sacrifice their own objective interests for the sake of others and for a therapist to assist them in this regard.

- Viewing therapy's point to be to foster meaningfulness avoids the objections facing rival, welfarist theories, while capturing their advantages.

- Supposing that therapy ought largely, if not exclusively, aim to foster meaning in clients' lives, a therapist would usefully invoke talk of "meaning" in order to clarify goals and dilemmas. There can be situations in which clients cannot avoid trade-offs between, e.g., happiness and meaning in life, and naming these competing values can assist self-understanding and decision-making.

- In addition, a therapist could encourage "deathbed reflection" on the part of clients, asking them to consider what about their life they would like to take pride in before dying, or what about it they would like others to admire in a eulogy.

\footnotetext{
${ }^{10}$ For comments on a previous draft of this chapter, the author thanks Dan Stein, Pedro Tabensky, and the editors of this volume. Special thanks to Michael Lacewing.
} 
Such a perspective encourages attention to what is intuitively important, and fosters reflection on narrative values, including posthumous ones.

- Finally, it can be worth reminding clients of the worth of meaningfulness in the face of continued suffering or the inability to develop a suitably strong self. Despite lacking welfare, clients might be able to achieve purposes that help others, disclose truth, or create beauty. That is something for clients, and a therapist, to grab on to when times are hard.

\section{References}

Adler, A., Boniwell, I., Gibson, E., Metz, T., Seligman, M., Uchida, Y., et al. (2013). Definitions of terms. In I. Boniwell \& S. Alkire (Eds.), Report on wellbeing and happiness (pp. 19-34). Thimphu: Centre for Bhutan Studies.

Bader, M. (1994). The tendency to neglect therapeutic aims in psychoanalysis. Psychoanalytic Quarterly, 63, 246-270.

Baumeister, R., \& Vohs, K. (2002). The pursuit of meaningfulness in life. In C. R. Snyder \& S. Lopez (Eds.), Handbook of positive psychology (pp. 608-618). Oxford: Oxford University Press.

Boniwell, I., \& Henry, J. (2007). Developing conceptions of well-being. Social Psychology Review, 9, 3-18.

Delle Fave, A., Massimini, F., \& Bassi, M. (2011). Psychological selection and optimal experience across cultures. New York, NY: Springer.

Diener, E., Suh, E., Lucas, R., \& Smith, H. (1999). Subjective well-being: Three decades of progress. Psychological Bulletin, 125, 276-302.

Fairbairn, W. R. D. (1958). On the nature and aims of psychoanalytical treatment. International Journal of Psychoanalysis, 39, 374-383.

Fink, B. (2010). Against understanding: Why understanding should not be viewed as an essential aim of psychoanalytic treatment. Journal of the American Psychoanalytic Association, 58, 259-285.

Frankl, V. (1984). Man's search for meaning (Rev. ed.). New York, NY: Simon \& Schuster Inc.

Freud, S. (1930). Civilization and its discontents. J. Strachey (Trans.), Repr. New York, NY: W. W. Norton \& Company, 1961.

Fromm, E. (1956). The art of loving. Repr. New York, NY: Perennial Library, 1989.

Habermas, J. (1971). Knowledge and human interests. J. Shapiro (Trans.), Boston, MA: Beacon Press.

Horney, K. (1950). Neurosis and human growth. New York, NY: W. W. Norton \& Company Inc.

Jung, C. (1953). The development of personality. Repr. In C. Moustakas (Ed.), The self (pp. 147-159). New York, NY: Harper Colophon Books, 1956.

Kahneman, D., Diener, E., \& Schwarz, N. (1999). Well-being: Foundations of hedonic psychology. New York, NY: The Russell Sage Foundation.

Kauppinen, A. (2012). Meaningfulness and time. Philosophy and Phenomenological Research, $82,345-377$.

Kohut, H. (1977). The restoration of the self. Chicago, IL: The University of Chicago Press.

Kohut, H., \& Wolf, E. (1978). The disorders of the self and their treatment. Repr. In P. Ornstein (Ed.), The search for the self: Selected writings of Heinz Kohut: 1978-1981 (Vol. 3, pp. 359386). Madison, WI: International Universities Press, 1990.

Kovel, J. (1976). A complete guide to therapy. London: Penguin Books Ltd.

LeBon, T. (2001). Wise therapy. London: Continuum.

Maslow, A. (1950). Self-actualizing people: A study of psychological health. Repr. In C. Moustakas (Ed.), The self (pp. 160-194). New York, NY: Harper Colophon Books, 1956. 
Masterson, J. (1990). The search for the real self. New York, NY: The Free Press.

May, R. (1989). The art of counselling. New York, NY: Gardner Press.

Metz, T. (2001). The concept of a meaningful life. American Philosophical Quarterly, 38, 137-153.

Metz, T. (2012). The meaningful and the worthwhile: Clarifying the relationships. The Philosophical Forum, 43, 435-448.

Metz, T. (2013a). Meaning in life: An analytic study. Oxford: Oxford University Press.

Metz, T. (2013b). Meaning in life as the aim of psychotherapy: A hypothesis. In J. Hicks \& C. Routledge (Eds.), The experience of meaning in life: Classical perspectives, emerging themes, and controversies (pp. 405-417). Dordrecht: Springer.

Miller, A. (1979). The drama of the gifted child: The search for the true self. R. Ward (Trans.), Repr. New York, NY: Basic Books, 1981.

Nozick, R. (1974). Anarchy, state, and utopia. New York, NY: Basic Books.

Orr, R., \& Genesen, L. (1997). Requests for "inappropriate" treatment based on religious beliefs. Journal of Medical Ethics, 23, 143-147.

Rogers, C. (1957). A therapist's view of the good life. Repr. In his On becoming a person: A therapist's view of psychotherapy (pp. 183-196). Boston, MA: Houghton Mifflin Company, 1961.

Ryan, R., \& Deci, E. (2001). On happiness and human potentials: A review of research on hedonic and eudaimonic well-being. Annual Review of Psychology, 52, 141-166.

Ryff, C. (1989). Happiness is everything, or is it? Explorations on the meaning of psychological well-being. Journal of Personality and Social Psychology, 57, 1069-1081.

Ryff, C. (2014). Psychological well-being revisited: Advances in the science and practice of eudaimonia. Psychotherapy and Psychosomatics, 83, 10-28.

Storr, A. (1960). The integrity of the personality. Repr. New York, NY: Ballantine Books, 1992.

Taylor, C. (1989). Sources of the self: The making of the modern identity. Cambridge, MA: Harvard University Press.

Winnicott, D. W. (1955). Clinical varieties of transference. Repr. In M. Khan (Ed.), Through paediatrics to psycho-analysis (pp. 295-299). London: The Hogarth Press and the Institute of Psychoanalysis, 1978.

Winnicott, D. W. (1960). Ego distortion in terms of true and false self. Repr. In his The maturational process and the facilitating environment (pp. 140-152). New York, NY: International Universities Press, 1965.

Yalom, I. (1980). Existential psychotherapy. New York, NY: Basic Books. 


\section{焦 Springer}

http://www.springer.com/978-3-319-41395-2

Clinical Perspectives on Meaning

Positive and Existential Psychotherapy

Russo-Netzer, P.; Schulenberg, S.E.; Batthyany, A.

(Eds.)

2016, XX, 455 p. 11 illus., 6 illus. in color., Hardcover

ISBN: 978-3-319-41395-2 